\title{
UNA PERSPECTIVA DESDE EL FEDERALISMO ALEMÁN
}

\author{
Mario Kölling \\ Profesor de Ciencia Política, \\ Universidad Nacional de Educación a Distancia. \\ Fundación Manuel Giménez Abad
}

Cómo citar este artículo / Citation: Kölling, M. (2021). Una perspectiva desde el federalismo
alemán. Tudela Aranda, J. (coord.)
Estado Autonómico y covid-19,
Colección Obras colectivas, Fundación Manuel Giménez Abad, Zaragoza.
DOI: $\underline{\text { https://doi.org/10.47919/FMGA.OC21.0208 }}$

SUMARIO: I. INTRODUCCIÓN - II. UNA BREVE REFLEXIÓN SOBRE EL FEDERALISMO ALEMÁN EN LA GESTIÓN DE LA CRISIS COVID-19 - III. UNA BREVE REFLEXIÓN SOBRE EL ESTADO AUTONÓMICO Y LA GESTIÓN DE LA CRISIS COVID-19 - IV. CONCLUSIONES

\section{INTRODUCCIÓN}

Aunque posiblemente existe una multitud de variables que permiten analizar las causas de la propagación de la covid-19 y la mortalidad durante las diferentes olas, p. ej. el comportamiento social, la estructura urbanística, el gasto en sanidad per cápita, el número de UCI por 100.000 habitantes o el número de rastreadores; la gestión de la pandemia de la covid-19 atrajo mucha atención sobre las diferentes formas de organización territorial del gobierno y su capacidad de enfrentarse a la pandemia. Lejos de intentar atribuir a la organización territorial un impacto decisivo en la propagación del virus, a continuación, se pretenden analizar brevemente algunos rastros característicos de los sistemas territoriales alemán y español y cómo estas características se han fortalecido o modulado en el último año. 
Considerando las limitaciones de este breve ensayo, no se va a entrar en un debate sobre los orígenes de la organización territorial ni de las diferencias en el sistema político y/o sistema de partidos. Solamente cabe mencionar que, a diferencia de la situación política de Alemania, que se encuentra desde hace una década en una situación económica favorable y con una gran estabilidad política, España lleva una década en modo crisis. La crisis económica y financiera ha provocado la llamada crisis de las instituciones representativas, en la que se ha producido una enorme pérdida de confianza popular en diversos aspectos del sistema democrático. De manera casi simultánea, el conflicto secesionista en Cataluña se intensificó en 2012, el sistema de partidos se atomizó y desde 2015 ningún partido ha podido establecer una clara mayoría de gobierno.

\section{UNA BREVE REFLEXIÓN SOBRE EL FEDERALISMO ALEMÁN EN LA GESTIÓN DE LA CRISIS COVID-19}

La Ley Fundamental de 1949 no reconoce el estado de emergencia o de alarma como sí lo hace la Constitución española, ya que este concepto y la idea asociada a un papel dominante del ejecutivo en situaciones de crisis están histórica e ideológicamente sesgados ${ }^{1}$. Sin embargo, aunque Alemania no ha entrado en un confinamiento total, el alcance de las medidas adoptadas por el Gobierno federal y los gobiernos de los Länder corresponden sin duda a una situación muy excepcional, pero revela también la capacidad de respuesta y la flexibilidad del sistema federal. La distribución territorial del poder ha garantizado una gestión cimentada en el principio de subsidiaridad y cooperación que a pesar de algunos conflictos se ha mantenido.

\footnotetext{
${ }^{1}$ En 1968 se incluyeron en la Ley Fundamental una serie de circunstancias excepcionales para una situación de defensa (Verteidungsfall) (art. 115), pero también en situaciones previas a una agresión armada (Spannungsfall) (art. 80) que deben de ser declarados por el Bundestag, y en el caso del art. 115 también por el Bundesrat. La emergencia interna (doméstica) (art. 91) y catástrofes naturales (art. 35) pueden ser declarados por el gobierno federal, pero tales dispositivos nunca han sido aplicados y no existen leyes para su desarrollo. Tampoco la crisis de COVID-19 presentó una situación de defensa, ni una agresión armada, ni se pudo constatar un peligro para el orden democrático de la Federación o de un Land. El art. 35 que se refiere principalmente a terremotos o inundaciones, prevé en el caso de que se active, una colaboración policial entre los Länder o la intervención del ejército en el interior, medidas que tampoco han sido adoptadas en la situación de pandemia.
} 
El sistema federal alemán se caracteriza por ser un federalismo cooperativo. Esto se manifiesta en los complejos procesos de coordinación a nivel horizontal entre las administraciones de los Länder y a nivel vertical, entre el Gobierno federal y los Länder. La necesidad de cooperación es, entre otros, resultado del gran número de materias de competencias concurrentes y responsabilidad compartida. Esta característica lleva a complejos procesos de toma de decisiones y la dificultad por parte de los ciudadanos de asignar responsabilidades. No obstante, desde el comienzo de la pandemia, las administraciones han podido apoyarse en los numerosos foros de cooperación intergubernamental existentes a nivel horizontal y vertical, como la conferencia de los primeros ministros, que cuenta con la participación de la Canciller, y las conferencias de los ministros sectoriales. Dentro de estos foros institucionalizados de cooperación intergubernamental y administrativa, se intercambiaron información y tomaron decisiones aplicables para todo el territorio de la República federal. La cooperación permanente y "burocratizada" y la heterogeneidad de los gobiernos de coalición de los Länder, que incluyen a casi todos los partidos políticos del espectro parlamentario, suavizaron los intereses partidistas o conflictos territoriales. Desde el 12 de marzo de 2020, se han celebrado numerosas reuniones oficiales entre los primeros ministros de los Länder con la participación de la Canciller Federal. La Canciller Merkel, aunque formalmente solo participó con la función de moderar el debate, ejerció también un rol importante en el proceso de toma de decisiones, si bien las decisiones adoptadas en estas reuniones no siempre reflejan la posición del Gobierno federal (casi siempre exigiendo medidas más estrictas), sino que normalmente prevalecen las preferencias de la mayoría de los gobiernos de los Länder (que abogaron por medias más moduladas).

Las reuniones a alto nivel se complementan con conferencias de los jefes de las cancillerías de los Länder y reuniones de los ministerios sectoriales. También se crearon órganos de coordinación gubernamental permanente entre los agentes del sistema de salud, y como consecuencia, la cooperación y el intercambio de información entre los agentes del ámbito sanitario y el organismo federal, el Instituto Robert Koch, funcionó sin grandes problemas.

La cooperación entre los otros ejecutivos dio como resultado negociaciones entre iguales, donde las decisiones se tomaron por unanimidad pero los gobiernos tuvieron también suficiente margen de maniobra y cobertura legal 
(Ley de Enfermedades Infecciosas, Infektionsschutzgesetz, IfSG) para sus decesiones propias.

La pandemia exige una actuación de las administraciones en diferentes materias, y el gran número de materias de competencia concurrente y responsabilidad compartida del federalismo alemán facilitó la cooperación trasversal y una reacción flexible. No se puede confirmar una tendencia hacia una centralización de la toma de decisiones, al contrario, el dominante rol de los gobiernos de los Länder en la toma de decesiones sobre las medidas de contención fue inusual. El Ministerio Federal de Sanidad ha dejado la definición de las ordenanzas de protección contra covid-19 en manos de los Länder y solo ha adoptado reglamentos que se refieren al registro de viajeros procedentes de otros Estados que no son competencia de los Länder. Decesiones unilaterales como por ejemplo sobre el cierre de los colegios en las primeras semanas de la pandemia por parte de algún Land o sobre el cierre temporal de las fronteras por parte del Gobierno federal no fueron habituales. Sin embargo, ante la mayor cooperación en los primeros meses de la pandemia, destaca el aumento de la conflictividad en paralelo con el aumento de las cifras de contagiados y fallecidos a partir de septiembre y el acercamiento de las elecciones en diferentes Länder.

El Estado federal alemán se caracteriza también por ser un federalismo unitario, que se refleja en el objetivo político y constitucional de crear condiciones de vida uniformes/equivalentes en todo el territorio de la República Federal. Frecuentemente se critica esta característica porque no se aprovecha la capacidad del federalismo como laboratorio de ideas y por la falta de competitividad entre las políticas públicas de los Länder. No obstante, ante la pandemia, se puede constatar una actuación rápida y uniforme por parte de las administraciones de los Länder. En la primera reunión del 12 de marzo entre los primeros ministros de los Länder y la Canciller Federal se acordaron limitaciones para reuniones en espacios públicos y el cierre de escuelas, siendo este acuerdo y los posteriores implementados inmediatamente por la totalidad de los Länder ${ }^{2}$. Sin embargo, tras varios meses de toma de decisiones de forma cooperativa, fue aumentando la disconformidad y oposición de

\footnotetext{
${ }^{2}$ En el acuerdo intergubernamental del 15 de abril de 2020, se adoptó una posición común sobre el uso de mascarillas. Entre el 20 y el 29 de abril, todos los Länder implementaron la obligación de llevar mascarillas en espacios cerrados.
} 
algunos primeros ministros ante las decisiones unitarias y se dificultó la definición de normas mínimas en toda la República Federal ${ }^{3}$.

Dentro de los límites establecidos por los acuerdos marco, se puede observar una amplia heterogeneidad en las normas y su aplicación entre los Länder ${ }^{4}$. Esta capacidad de autogobierno facilitó una reacción rápida y flexible y los reglamentos se adaptaron a las necesidades locales de la población. La divergencia en las políticas de los Länder puede ser explicada también por la competitividad entre intereses partidistas. Esta presión competitiva (especialmente entre los primeros ministros de Renania del Norte-Westfalia y Baviera como posibles candidatos a la cancillería) pero también oportunista, llevó a algunos primeros ministros a ciertos desvíos de los acuerdos conjuntos para destacar en su gestión propia, siendo más permisivos o más restrictivos. La divergencia de las medidas fue también consecuencia de las decisiones de los tribunales de los Länder y refleja también el reparto de poder -importante en momentos de restricciones de derechos fundamentales, p.e. cuando un Land decidió abrir las iglesias para el culto, otros se vieron "obligados" a seguir si no se detectaban efectos negativos para la vida y salud de las personas-. En este sentido, las restricciones sobre los derechos fundamentales fueron limitadas por la necesidad de justificarlas por 16 gobiernos. Por otro lado, ante la falta de certeza sobre las consecuencias de las decisiones tomadas en momentos de crisis, prevalecen las ventajas de una toma de decisiones descentralizada que evita que posibles consecuencias negativas se extiendan en un territorio más amplio. Por otro lado, la presión de la toma de decisiones conjuntas limitó a algunos Länder, por ejemplo a Mecklenburg Pomerania Occidental, con cifras de infecciones muy bajas, a avanzar con medidas de desescalada, lo que provocó en cierta medida una reducción en el apoyo de las medidas por parte de la población.

\footnotetext{
${ }^{3}$ Por ejemplo, en la reunión del 27 de agosto, tras un debate de 5 horas, y a pesar de las demandas para sanciones uniformes en el territorio alemán, solo se acordó una multa mínima de al menos 50 euros por violaciones de la obligación de llevar mascarilla en los espacios determinados. Aun así, el primer ministro de Sajonia-Anhalt se desvinculó del acuerdo y anunció que no se implementaría en este Land.

${ }^{4}$ Como ejemplo de la diversidad, se pueden mencionar las normas de cuarentena que impusieron los Länder para los viajeros que regresan de las zonas de riesgo. Ocho Länder introdujeron estas medidas desde el 15 de marzo y en otros cuatro la semana siguiente. Los restantes Länder siguieron el 23 de marzo (Renania-Palatinado), el 2 de abril (Berlín) y el 10 de abril (Sajonia y Sajonia-Anhalt).
} 
Las medidas de la desescalada hacia la "nueva normalidad" también fueron muy desiguales, lo que provocó la crítica de la Canciller sobre las "orgías de debate innecesarias sobre desescaladas" entre los Länder. Desde la opinión pública se criticó la diversidad de las decisiones políticas en los 16 Länder, que según estos argumentos llevó a la irritación de la población y socavó su comprensión de la necesidad de las medidas.

Más recientemente, durante la segunda ola y a las dos semanas del segundo cierre, el Gobierno federal quiso endurecer aún más las medidas, a lo que se opusieron muchos Länder. En ambas situaciones, el Gobierno federal tuvo que ceder. En lo que respecta a las relaciones federales, estas tensiones reflejan el papel asertivo de los Länder durante la pandemia de covid-19, pero, de nuevo, no condujeron a un conflicto intergubernamental real ${ }^{5}$.

Finalmente, el sistema federal alemán se describe como federalismo ejecutivo. Las competencias ejecutivas de los Länder superan sus competencias legislativas, puesto que ejecutan no sólo sus propias leyes, sino también, como regla general, las leyes federales. El enfoque en los ejecutivos y las burocracias ministeriales ha sido criticado como poco transparente y por la marginalización de los parlamentos de los Länder. Según la Ley Fundamental, las competencias en materia de salud se distribuyen entre la Federación y los Länder. La Federación tiene un poder legislativo concurrente en lo que respecta a las medidas para combatir las enfermedades que representan un peligro para la población o son transmisibles... (Artículo 74.1). Aunque las competencias en materia de salud son competencias compartidas, los Länder son responsables de la planificación de la capacidad hospitalaria. Las responsabilidades de la gestión de emergencias durante una crisis de salud pública se definen en la IfSG. La IfSG es una ley federal, pero, dada la distribución funcional de competencias, los Länder son los encargados de aplicarla. Más concretamente, la IfSG autoriza a los Länder a imponer medidas de contención en caso de pandemia (o epidemia). En este sentido, son los Länder los que tienen la competencia de toma de decisiones sobre las

\footnotetext{
${ }^{5}$ Véase Schnabel, J., The covid-19 crisis and German federalism, Cuadernos Manuel Giménez Abad, ํ․ 20, 2020, pp. 71-74. Tambien Behnke, N., Föderalismus in der (Corona-)Krise? Föderale Funktionen, Kompetenzen und Entscheidungsprozesse, Aus Politik und Zeitgeschichte, 37, 2020; Kölling, M., el Bundestag y el Bundesrat alemán en tiempos de COVID 19, Cuadernos Manuel Giménez Abad, monografia 8, 2020; Milbradt, G., Forum of Federations: Federalism and the COVID-19 crisis, A perspective from Germany, Cuadernos Manuel Gimenez Abad, 19, 2020.
} 
medidas y cuándo deberían ser aplicadas. Así pues, la IfSG otorga a los Länder un margen de maniobra importante que va más allá del típico del federalismo administrativo. La IfSG asigna al Gobierno federal el papel de coordinador, pero no le permite imponer medidas de contención por sí mismo. Sin embargo, la Federación asumió el rol principal en la confección y financiación de las medias económicas directas e indirectas. Este hecho es otro factor decisivo para explicar la gestión. La federación podía apoyarse en la administración de los Länder muy eficaz y bien engrasada en la implementación de normas propias y federales.

El federalismo ejecutivo se refiere también al rol del gobierno. El rol dominante del ejecutivo durante la pandemia se ha traducido en la marginalización de los parlamentos. Los acuerdos intergubernamentales sobre las medidas de distanciamiento social y sobre cómo se debían definir las medidas para la desescalada, no fueron debatidos ni aprobados por el Bundestag, y tampoco por el Bundesrat y los parlamentos de los Länder. Sin embargo, con el paulatino incremento de medidas discrecionales por parte de los Länder los parlamentos de los Länder asumieron un rol más destacado.

Las medidas adoptadas provocaron también críticas y confrontaciones políticas expresadas en varias manifestaciones. Sobre todo, el perfil bajo del Bundestag y las implicaciones para el sistema federal avivaron críticas sobre el declive del sistema democrático, que ponía en peligro el sistema político establecido por la Ley Fundamental.

En consecuencia, algunos parlamentos de los Länder exigieron más poderes de veto. En enero 2021, Berlín adoptó la llamada "ley de participación parlamentaria de COVID-19" (Parlamentsbeteiligungsgesetz), que faculta al parlamento a plantear una objeción contra los decretos ley existentes. El parlamento también debe dar su visto bueno a las prórrogas de los decretos-ley que afecten a los derechos fundamentales.

\section{UNA BREVE REFLEXIÓN SOBRE EL ESTADO AUTONÓMICO Y LA GESTIÓN DE LA CRISIS COVID-19}

Mientras que el sistema federal de Alemania es un ejemplo de gobierno compartido con diversos foros horizontales y verticales institucionalizados de 
cooperación, a falta de una previsión constitucional o tradición institucional de régimen compartido entre las CCAA, las relaciones intergubernamentales en España se desarrollaron principalmente a iniciativa del Gobierno central en una vertiente vertical. Además, la cooperación intergubernamental se caracterizó inicialmente como cooperación interadministrativa, y la mayor parte de la interacción intergubernamental tuvo lugar en el ámbito parlamentario y dentro del ámbito de los partidos políticos. Finalmente, en términos generales, el sistema se puede caracterizar por un fuerte enfoque bilateral; la falta de interacción horizontal y por un enfoque profundamente sectorial; un enfoque de ejecución administrativa; y una gran diversidad ${ }^{6}$. Además, los foros sectoriales intergubernamentales otorgan a las autoridades del Gobierno central un papel muy esencial en la definición del orden del día y de la convocatoria de las reuniones.

A pesar de que durante los últimos años se puede constatar un desarrollo importante, la ausencia de mecanismos estables de cooperación y coordinación se hicieron visibles al principio de la pandemia hasta la declaración del estado de alarma. Tras la declaración del estado de alarma, en una videoconferencia celebrada el 15 de marzo de 2020, el Presidente del Gobierno informó a los presidentes de las CCAA sobre las medidas adoptadas. Tras la reunión se hizo público un manifiesto institucional en el que casi la totalidad de los Presidentes de las CCAA confirmaron su compromiso con la "unidad de acción" y la lealtad. Durante el primer estado de alarma, estas reuniones virtuales del Presidente del gobierno con los Presidentes de las CCAA dentro del seno del Senado, se convirtieron en el principal foro de coordinación, consulta y concertación para la gestión de la pandemia. La mayoría de los Presidentes de las CCAA destacaron la utilidad de la Conferencia de Presidentes a pesar de su carácter puramente informativo en la gestión de la pandemia.

Además, el Consejo Interterritorial del Sistema de Salud tuvo un papel destacado. A lo largo del estado de alarma, se reunió de manera virtual dos veces por semana, no solo para intercambiar información, sino también para llegar a acuerdos. En total se celebraron 82 reuniones del Consejo interterritorial en 2020 (en 2019: 5). También otras conferencias sectoriales

6 Pérez-Medina, J. M., Dinámica de las Conferencias Sectoriales. Entre la Intergubernamentalidad y la Cooperación Administrativa, Revista d'Estudis Autònòmics $i$ Federal-Journal of Self-Government, 31, 2020, pp. 17-64. 
aumentaron en el número de reuniones, en total se celebraron 166 conferencias sectoriales (2019: 49) ${ }^{7}$. Otros mecanismos intergubernamentales de menor perfil experimentaron un crecimiento en el número de las reuniones durante el año 2020.

A finales de mayo, el Gobierno de España introduce, con la llamada "cogobernaza", un nuevo término en el contexto español que, a pesar de la falta de concreción, trasmitía connotaciones no jerárquicas de la cooperación, pero sin llegar a la codecisión. En concreto, una orden ministerial ${ }^{8}$ regula el procedimiento que deberían seguir las CCAA para la elaboración, remisión y tramitación de propuestas de desescalada. Según Carolina Darias, en ese momento Ministra de Política Territorial, el plan para pasar del estado de alarma a la "nueva normalidad" a finales de junio se elaboró en estrecha colaboración con las $\mathrm{CCAA}^{9}$.

Una vez que las CCAA hubieron asumido de nuevo sus competencias durante la "nueva normalidad", los diferentes foros de reuniones fueron convocados con menor intensidad. Pero también podemos encontrar ejemplos de la toma de decisiones compartida. A finales de septiembre, se acordaron entre el Gobierno central y la mayoría de los gobiernos de las CCAA unos indicadores específicos para imponer restricciones en las zonas de más de 100.000 habitantes. Además, la decisión sobre el segundo estado de alarma del 25 de octubre, tampoco fue decidida de forma unilateral por parte del Gobierno central, sino a petición y en coordinación con las CCAA.

En cuanto a las relaciones entre los gobiernos de las CCAA, la dimensión horizontal ha estado tradicionalmente menos desarrollada; tampoco durante la pandemia se establecieron instrumentos adicionales o extraordinarios de cooperación horizontal entre ellas. La cooperación horizontal se limitó principalmente a acuerdos bilaterales entre CCAA vecinas.

A diferencia del bajo nivel del gobierno compartido, el autogobierno está muy marcado en el Estado Autonómico, por lo que no sorprende que España

\footnotetext{
${ }^{7}$ https://www.mptfp.gob.es/portal/politicaterritorial/autonomica/coop_autonomica/Conf_Sectoriales/Conf_Sect_Reuniones.html

${ }^{8}$ Orden SND/387/2020 de 3 de mayo de 2020

${ }^{9}$ https://www.mptfp.gob.es/va/dam/es/portal/prensa/Entrevistas/Ministra/ENTREVISTA_VOCEN TO.pdf.pdf
} 
tampoco pueda ser considerado como un Estado descentralizado unitario. A diferencia de Alemania, España partió en los años setenta de un Estado fuertemente centralizado y unitario. En los últimos años muchos analistas han considerado las diferencias en las políticas públicas y la asimetría institucional en el Estado Autonómico como ventajas para acomodar la diversidad de España; sin embargo, otras corrientes lo consideran como una amenaza para el mercado interior y como signo de debilidad del Gobierno central para garantizar condiciones de vida similares en todo el territorio. En lo que se refiere a la gestión de la pandemia, destaca que durante el estado de alarma se adoptaron las decisiones de manera uniforme para todo el territorio de España. La ejecución por parte de las CCAA llevó a diferencias importantes.

La desescalada asimétrica abría la posibilidad de una toma de medidas específicas en las CCAA, en muchas ocasiones sin consultar a las CCAA limítrofes. Sin embargo, los indicadores acordados entre el Gobierno central y la mayoría de los gobiernos de las CCAA a finales de septiembre, mencionados anteriormente, representan un ejemplo de la definición de un marco común ante el incremento del número de infectados por la covid-19. Asimismo, el segundo estado de alarma a nivel nacional, a partir del 25 de octubre, no solo ofrecía cobertura jurídica a las CCAA para limitar los derechos fundamentales, sino que se establecieron también determinadas medidas de restricciones aplicables en todo el territorio. Dentro de estos límites acordados de forma conjunta entre el Gobierno central y las CCAA, estas últimas fueron adaptando las restricciones en su territorio. Sin embargo, a diferencia del caso alemán, donde los acuerdos marco intergubernamentales fueron adaptados a las situaciones concretas, el marco del estado de alarma fue mucho más rígido para adecuarlo a las condicionantes cambiantes.

Considerando las reflexiones anteriores, se puede afirmar que existe gran similitud entre ambos sistemas en lo que se refiere al rol dominante del ejecutivo. Resalta en el caso de España las competencias de ejecución por parte de las CCAA. Desde 2001, las CCAA han desarrollado una gran capacidad administrativa para aplicar la normativa nacional y para desarrollar sus políticas propias. Las CCAA son responsables de la toma de decisiones y de la gestión en el ámbito de sanidad desde hace dos décadas, aunque no tienen las competencias exclusivas en esta materia. La competencia de coordinación del Gobierno central ha sido ejercida durante este tiempo de 
forma muy limitada. Por ello, el Ministerio de Sanidad tenía dificultades para obtener los datos operativos básicos, así como para coordinar las acciones conjuntas con las CCAA, por ejemplo, la organización de la adquisición conjunta de equipos de protección individual y la gestión de datos.

En lo que se refiere al domino del ejecutivo. La pandemia ha provocado graves interferencias en el funcionamiento del Congreso de los Diputados, ya que su actividad parlamentaria se redujo al mínimo. Esta situación reforzó la tradicionalmente débil posición del parlamento español frente al ejecutivo. Sin embargo, a diferencia del Bundestag, el Congreso mantuvo una importante influencia a través de su papel en la aprobación del estado de alarma y sus posteriores prórrogas. Una vez superado el estado de alarma, el Congreso recuperó sus funciones constitucionales, tanto en lo que se refiere al proceso legislativo como al control de la actuación del Gobierno. Sin embargo, las comparecencias del Presidente del Gobierno se limitaron a una sesión informativa cada dos meses y aunque el Ministro de Sanidad compareció cada mes, esto supone una disminución de la intensidad del control parlamentario ${ }^{10}$.

\section{CONCLUSIONES}

Frecuentemente el elevado número de infecciones y muertes en España se ha asociado a la tardía reacción de los gobiernos central y autonómicos, y a la escasa coordinación entre las autoridades centrales y de las CCAA. Por otro lado, el federalismo cooperativo alemán fue considerado como elemento para explicar el reducido número de infecciones y muertes. La evolución de la pandemia ha demostrado que esta casuística no se sostiene.

No obstante, aplicando los rasgos del federalismo alemán a la gestión de la crisis covid-19, y basándonos en los datos empíricos, se puede confirmar lo siguiente: la crisis de la covid-19 ha revelado sobre todo las debilidades estructurales del modelo territorial español. En particular, se ha puesto de manifiesto que los instrumentos de coordinación intergubernamental verticales y horizontales y los órganos de decisión conjunta fueron insuficientes para responder adecuadamente a la crisis. Sin embargo, durante la crisis, la

\footnotetext{
${ }^{10}$ García-Escudero Márquez, P., Actividad y funcionamiento de las Cortes generales durante el estado de alarma por COVID-19, Cuadernos Manuel Giménez Abad, Monografía 8, 2020.
} 
coordinación y la toma de decisiones comunes entre los niveles de gobierno mejoraron y alcanzaron niveles sin precedentes en todos los ámbitos.

El análisis confirma la eficacia y la robusta coordinación entre los Länder y el nivel federal. La cooperación permanente entre el Gobierno federal y los gobiernos de Länder contribuye a un debate permanente sobre las opciones políticas, lo que sin duda facilita la toma de decisiones de forma moderada y consensuada. Pero también las decisiones tomadas de forma descentralizada se adaptaron a las necesidades locales de la población, se evitó una concentración del poder y se incrementó la eficiencia de las medidas ante situaciones de emergencia local. En vista de ello, el federalismo ofrece un orden institucional que permite experimentar con soluciones diferentes a los problemas. 